\title{
The Role of Routines in The Technological Learning of The University - Company Interaction: The Case UFSC and Petrobras
}

\author{
Paola Azevedo ${ }^{1^{*}}$, Silvio Antônio Ferraz Cario ${ }^{1}$
}

\begin{abstract}
This study aims to identify the role of routines in the technological learning of the interaction between the Federal University of Santa Catarina and Petrobras. A field research was carried out, through interviews with researchers and director from UFSC and managers from PETROBRAS. The data were transmitted through a content analysis, based on categories linked to the roles of the routines. The creation of routines such as team composition, task division by specialty, periodic group meetings and meetings with the company led to the generation of learning by searching and by interacting, both at the University and in the company.
\end{abstract}

Keywords: University-Company Interaction; Routines; Technological Learning; UFSC; Petrobras.

Submitted: January 21st, 2021 / Approved: April 26th, 2021

\section{Introduction}

The University-company interactions are essential for the generation and sharing of knowledge that support the technological learning process. For Suzigan, Albuquerque and Cário (2011) on the side of universities and research institutes, the generation of scientific knowledge is observed, which is aggregated by companies and, as they concentrate technological knowledge, it incites new questions for the elaboration scientific.

From the search, routine and selection existing in U-C interactions, the technological learning process is generated, which can be elucidated from the understanding that the economic environment is constantly evolving and the processes of change are endowed with characteristics such as irreversibility and cumulativeness, essential for the generation of innovation.

The routines are tacit behavior of production and reproduction and conducive to the creation of a memory in relation to the organization's actions, which generates a more effective performance on the part of the organization (NELSON, 2006). Milagres (2011) clarifies that routines are patterns of behavior that generate rules and result from them, and expectations of predetermined responses based on triggers. The triggers are related to specificities in terms of organizational context, so there is a tendency for patterns to adopt pre-established behavior patterns considering different possibilities.

The identification of the role of routines in U-E interactions allows the understanding of the construction of technological learning in a historical perspective. In this sense, the proposal of the present study is linked to two relevant actors for the Brazilian National Innovation System, the Federal University of Santa Catarina (UFSC) and Petrobras. In twenty years (1998 to 2018) the PETROBRAS was responsible for more than $90 \%$ of the investment in RD\&I made in the Brazilian Oil and Gas Sector, totaling R \$ 13.9 billion. The UFSC is among the universities that receive the most funds from Petrobras to carry out RD\&I.
Considering the UFSC and Petrobras relationship marked by a historical trajectory of interaction of approximately three decades, the importance of technological learning for Brazilian economic development, the relevance of these actors in the SNI, and the successful trajectory in the development of cutting edge technology in this partnership, the purpose of this study is to identify the role of routines in the technological learning of this interaction. To this end, this study is structured in six sections. In this first, the objective of the study is presented, followed by the discussion section of the theoretical-analytical framework on U-E interaction in the evolutionary perspective; in the third, the methodology is described; in the fourth, innovative procedures are presented and analyzed, focusing on the role of routines and the technological learning of interaction. At the end, the main conclusions and references used are presented.

\section{Innovative procedures and the technological learning process}

The emergence and consolidation of the paradigm and technological trajectory occur based on innovative search, routine and selection procedures. Nelson and Winter (1982) explain the behavior of companies through these procedures, which are endowed with growth patterns assimilable to routine, which by the analogy used by the authors is seen as the genetic load of the company. Thus, the routines can be considered the genes of companies and dictate a probable behavior, since in this "genetic load" there is an inheritance of behaviors of the company that develops certain paths for the future. For Nelson and Winter (2006 p.151) routine is a "repetitive pattern of activity in an entire organization, an individual skill, or - as an adjective - regular and incident-free effectiveness of organizational or individual performance".

The routine is a predictable and regular behavior structure that generates schemes of repeated activities and is characterized by repetition and experimentation, which results in a progressive improvement of the tasks performed, enabling the continued creation of new operating

1) Federal University of Santa Catarina, Florianópolis, Brazil

*Corresponding author: paola.azevedo@ufsc.br 
opportunities (CORAZZA; FRACALANZA, 2004). The creation of activity routines in a company is essential, as it allows the stock of specific operational knowledge and generates a memory capable of characterizing different companies (NELSON, 2006). The routines have different roles in the innovation process, such as: organization's memory, truce, goal in controlling the organization, in the reproduction of existing routines and in imitation of those used by other organizations.

In the routine as memory, the routine is consolidated by its own event, because the organization "remembers doing". The routine as a truce is linked to internal conflicts within the organization that are part of the routine operation, because there are cases of divergences between the interests of the organization and the members that constitute it.
This routine acts in the sense of allowing a truce in these conflicts as it allows the creation of a symbolic culture shared by all.

In the routine as a goal there are three possibilities of occurrence, such as control, copying and imitation. The routine can be seen as control when it assumes the role of a standard to be fulfilled. The copy concerns the assumption that it is possible to reproduce a routine by establishing the same routine in a company similar to the original. The imitation means using the same routine, for example, in larger proportions, or as a strategy, in the case of another company (NELSON; WINTER, 2006). Milagres (2011) presents the main roles of routines, as well as their respective description, that was found in the literature, as shown in Chart 1.

Chart 1. The roles of routine

\begin{tabular}{|c|c|c|}
\hline $\begin{array}{l}\text { Provide coordination, } \\
\text { control and coherence }\end{array}$ & $\begin{array}{l}\text { Routines provide structure for the company's actions, } \\
\text { sequences and uniformity. }\end{array}$ & $\begin{array}{l}\text { Becker (2005); Dosi et al. (2000); Nelson and Winter (1982); Cohen and } \\
\text { Bacdayan (1994); Cyert and March (1963); Langlois (1992); Narduzzo, } \\
\text { Rocco and Warglien (1997); Becker (03- 06); Knot and McKelvey (1999); } \\
\text { Sherer, Rogovsky andWright (1998). }\end{array}$ \\
\hline Act as triggers & They can be triggered and trigger other routines. & $\begin{array}{l}\text { Nelson (1994); Becker (03-06); Betsch, Fiedler and Brinkmann (1998); } \\
\text { Weick (1990); Avery (1996); Cohen and Bacdayan (1994). }\end{array}$ \\
\hline Minimize conflicts & $\begin{array}{l}\text { Routines mediate issues related to the power struggle } \\
\text { and conflicts. }\end{array}$ & $\begin{array}{l}\text { Nelson and Winter (1982); Lazaric, Mangolte and Massué (2000); Inam } \\
\text { (1997); Becker (03-06); Cyert, March and Simon (1997); Denis and La- } \\
\text { zaric (1999, mimeo). }\end{array}$ \\
\hline Reduce the uncertainty & $\begin{array}{l}\text { They simplify, reduce the complexity of decisions, in- } \\
\text { crease confidence in the standards adopted and, with } \\
\text { that, reduce the uncertainty. }\end{array}$ & $\begin{array}{l}\text { Becker (2001; 1988); Vanberg (1993); Simon (1979); Hodgson (2000); } \\
\text { Dosi et al. (1993); Dosi and Egidi (1991); Becker and Knudsen (2000, mi- } \\
\text { meo); Avery (1996). }\end{array}$ \\
\hline $\begin{array}{l}\text { Reduce the use of cogni- } \\
\text { tive resource }\end{array}$ & $\begin{array}{l}\text { Routines allow automatic actions and thereby free up } \\
\text { cognitive space. }\end{array}$ & $\begin{array}{l}\text { Becker, (03-06); Becker and Knudsen (2001); Simon (1977); Egidi and } \\
\text { Narduzzo (1997); Egidi (1996); Hegselmann and Terna; Heidelberg, } \\
\text { Springer and Verlag; Ashmos, Duchon and McDaniel (1998). }\end{array}$ \\
\hline
\end{tabular}

Source: Milagres, 2011

The Chart 1 presented by Milagres (2011) illustrates the roles and description of the routines, as well as the main authors to address each one. According to the author, the routines offer coordination, control and coherence, as they support the company's actions, sequences and uniformity; they act as a trigger, since they can be triggered and trigger other routines; minimize the conflict, given the mediation provided by them on issues related to the dispute of power and conflicts; they reduce the uncertainty, as they simplify and reduce the complexity of decisions, increase confidence in the adopted standards and, consequently, reduce the uncertainty; they incorporate knowledge, since they are the memories of organizations, the locus of knowledge; and, finally, they reduce the use of cognitive resources, by virtue of allowing automatic actions, freeing cognitive space.
Nelson (2006) complements the routine's information, when stating that the hierarchy formats, as well as their change processes, are obtained through search. This is because the poorly adapted routines that become insufficient or useless generate a search for new routines that result in a greater benefit. In this way, the search and selection process enables the identification of appropriate routines for the various types of existing companies, making it a detailed and particular process dependent on internal and external factors. The search process is a set of activities and strategies developed and applied by the company in order to obtain a competitive advantage and perfect its technology to take advantage of the existing possibilities, as the search allows it to have access to and evaluate possible changes in products and processes. 
Nelson and Winter (2006) present the characteristics of the search that distinguishes it from other processes, what they called key characteristics, which are interrelated, due to the fact that the search processes are historical and non-repetitive. These are irreversibility, the contingent character and its dependent relationship with what is "out there" and available to be discovered and its fundamental uncertainty. The search's policy of companies will depend on the possibilities of finding "new routines" due to other variables, such as internal factors - the scientific and technological knowledge base, the previous performance in the innovative search, the consistency in the different product options and the its organizational, administrative and personnel capacity and competence - and external - the economic environment of insertion of the company, the current scientific and technological paradigm, information sources external to it and the way in which competitors operate.

The notion of selection complements the search's procedure, as these are simultaneous and interactive in the evolutionary process. The concomitant action of search and selection over time enables the evolution of organizations. The selection process corresponds to the mechanism for choosing innovations exercised by the environment, in which the market plays a central role, even though the process benefits from contributions from companies and institutions. Considering the flow of new innovations, the selection environment dictates the ways of adopting technologies over time, and there are no elements that guarantee the market mechanisms a favorable selection on which direction should be followed (DOSI, 2006; NELSON; WINTER, 2006).

The routine and the search make it possible to confirm that innovation goes beyond an optimization calculation, as it acts as a resource for a heuristic. The heuristic is a method or process designed to discover solutions to a given problem, thus, the heuristic that characterizes the search is based on limited human knowledge accumulated over time, which even without the intention of reaching the optimal solution provides the creation of innovations (NELSON; WINTER, 1982). The main factors of the presented analogy are the mechanisms of variation (mutation) and selection. This corresponds to the selection of the respective routines carried out by the market. That refers to the economic innovation generated within the company through the search process and not spontaneously (POSSAS 2008). This approach - for supposedly operating in an evolutionary, more realistic and dynamic context - is advantageous in relation to the correspondents in the orthodox (neoclassical) conception, the rational-maximizing individual behavior and the market balance are exchanged for the market trajectories (NELSON; WINTER, 1982).

From the search, routine and selection, the technological learning process is generated, which can be elucidated from the understanding that the economic environment is constantly evolving and the change processes are endowed with characteristics such as irreversibility and cumulativeness, essential for the generation of innovation. In this context, Johnson and Lundvall's (2005) approach to learning economics is appropriate to debate the accelerated technical, social and economic changes that support the formation and destruction of specialized knowledge, which ratifies the relevance of the ability to learn on economic performance. In this, the process is valued more than the product, personal contact and interaction to reach new knowledge and technologies.

The realization of economic activity enables the development of learning, which is a process that comes from repetition and experimentation, which allows activities to be carried out quickly and efficiently (DOSI; TEECE; WINTER, 1992). The learning is the acquisition of various types of knowledge, skills and capabilities that result in a greater chance of success in relation to the goals pre-established by the learning agents, which can be individuals or organizations (JOHNSON; LUNDVALL, 2005). The knowledge is linked to the activation of information in the human mind and it is subdivided into: tacit (manifested implicitly) and explicit (LUNDVALL, 2006b).

The new knowledge results from the dynamic interaction of this knowledge. There are three main differences between them. The first is how to code it and the transfer mechanism. The explicit knowledge can be verbalized or communicated in symbolic ways, through projects, computer programs, among others, so it is easily "abstracted", stored and shared, without the need for a "subject to know". The tacit knowledge, on the other hand, is intuitive, not articulated and there are great difficulties in coding and transferring it, it is known as subjective, as it can only be transmitted by example or observation and depends on a close and trusting relationship between the one who shares the knowledge and the "apprentice" (LAM, 1998).

The second dissonance between tacit and explicit knowledge is related to the acquisition and accumulation of knowledge. The explicit can arise from the logical deduction and its acquisition can occur through formal study. In turn, the tacit knowledge is acquired through practical experience, that is, by doing, which means that the acquisition and accumulation of knowledge will depend on the quality and quantity of experiences, as well as on its relationship with the individual's context. The third issue that differs from this presented knowledge is the potential for aggregation and forms of appropriation. The explicit knowledge shows the ease of coding and aggregating knowledge in a single location and its storage in an objective and appropriate manner without the need for a specific holder behind the subject. In the tacit, it is difficult to aggregate and store it in objective forms, as knowledge is personal and contextual.

The tacit knowledge is linked to the individual or organization, so it can only be obtained by hiring qualified individuals or by merging with other organizations (JOHNSON; LUNDVALL, 2005). This knowledge is crucial in the constitution of organizational knowledge, especially in the apprehension and conversion of the individual's tacit knowledge into collective. Thus, an organization's learning and innovative capacity are dependent on the organization's competence in mobilizing the tacit knowledge and enabling its interaction with explicit knowledge (NONAKA; TAKEUCHI, 1995).

The knowledge can also be classified into four categories: know-what, know-why, know-how and know-who (LUNDVALL, 2006a). The know-what is knowledge about the facts, that is, it is information that 
can be transformed into data. The know-why is related to knowledge around the principles and laws of movement in nature, in the human mind and in society. This knowledge proved to be important for the most effective technological development in certain areas of basic science, such as the electrical, electronic and chemical industries. The know-how is essential in economic activities and it includes the ability to do something specific based on standards linked to the individual's learning and experience. The know-who is the knowledge whose information relates to "who knows what" and "who knows what to do".

The elucidation of the types of knowledge facilitates the understanding of learning, which is a cumulative process internal or external to the organization, commonly path dependent, because the assimilation of advanced information depends on the past trajectory, that is, on previous training. According to Malerba (1992), there are six types of internal and external learning processes: learning by doing, learning by using, learning from advances in science and technology, learning from inter-industry spillovers, learning by interacting and learning by searching. The learning-by-doing is a learning mechanism internal to the organization and is related to new ways of doing linked to the production process (MALERBA, 1992; TIGRE, 2006). It is based on the experience, capacity and knowledge of the worker to promote technical changes. As it is a process in which you learn by doing, there is a continuous development correlated to production skills, which result in constant modifications, improvement and incremental innovations in processes and products (ROSENBERG, 2006). The learning-by-using is internal to the organization, linked to inputs, equipment and software, it occurs through the use and consumption of the product and it creates conditions for continuous changes (TIGRE, 2006).

The combination of learning by doing (internal learning to the organization - by production) and learning by using (learning resulting from the market - by use), originates learning by interacting (learning by interaction), resulting from the interactivity between producer and consumer. This has been widely used by high technology sectors, as it results from the qualified exchange of information between the producer and the consumer (ROSENBERG, 2006). The learning by interacting with suppliers generates technological information flows and innovative partnerships. The learning by searching is internal to the organization through information search processes and $\mathrm{R} \& \mathrm{D}$ activities that lead to problem's solving and the aggregation of new knowledge, and it aims to originate incremental and radical innovations. The learning from advances in science and technology is external to the organization and is related to the absorption of new knowledge from the international S\&T system (MALERBA, 1992; TIGRE, 2006).

As mentioned, the transmission of knowledge in the learning processes can be formal or informal and to occur simultaneously. These processes go beyond formal R\&D activities, which are characterized by the dissemination of codified knowledge and ownership by the company, and also include learning from informal sources, characterized by mechanisms that enable interactions between companies and other agents and in which knowledge is found. It is disseminated by the company and is not freely appropriable. This because the encoded content and the possibility of formal transfer are low, thus requiring observation and practice (MALERBA; ORSEGINO, 1993; CASSIOLATO; CAMPOS; STALLIVIERI, 2007).

\section{Methodology}

It is a qualitative research, case study, descriptive, documentary and bibliographic. Thus, the aim was to identify the role of routines in the technological learning of UFSC and Petrobras interaction.To this end, the mapping of all projects carried out by UFSC and Petrobras was initially carried out through the websites of the foundations that carry out the intermediation of the RD\&I projects, the Foundation for Teaching and Engineering of Santa Catarina (FEESC) and the Research Support Foundation University Extension (FAPEU), from December 2014 to December 2015. For validation of the partnership projects, the UFSC's Department of Technological Innovation (DIT) was consulted, which is currently called the Secretariat of Innovation (SINOVA).

After mapping the projects, twenty-seven research laboratories were identified in interaction with Petrobras, which totaled fifty-nine research projects in this period. The selection of coordinators of laboratories participating in the research took place due to accessibility and taking into account the laboratories that have interacted with the company for over twenty years, and that together account for more than $50 \%$ of the projects carried out in partnership with PETROBRAS: the Laboratory of Porous Media and Thermophysical Properties (LMPT), 8 projects; Metrology and Automation Laboratory (LAB / METRO), 4 projects; Heat Pipe Laboratory (LABTUCAL), 4 projects; Groundwater Remediation Laboratory (REMAS), 3 projects; Refrigeration and Thermophysics Research Laboratory, 3 projects; and, Intelligent Field Automation Laboratory, 2 projects.

Once the laboratories were selected, it was decided to conduct a semi-structured interview with the researchers of each one of them, since the projects are linked to each laboratory. In addition to the researchers, in order to understand the entire interaction process, the director of DIT, currently SINOVA, the sector for which interaction contracts are signed, was interviewed. From the first group of interviewees (researchers from UFSC and DIT's board), Petrobras contacts responsible for the interaction with the UFSC laboratories under study were identified, who were also interviewed. The interviews took place from August 2015 to 2016. The identification of the interviewees throughout the study was carried out through the classification E1 to E9, with E1 to E7 having the interviewees linked to the University, the six laboratory coordinators and the director of DIT. The company's representatives were classified as E8 and E9.

The data were analyzed through content analysis, based on previously defined categories, based on the evolutionary perspective, and with the support of qualitative data analysis software NVIVO. The previously defined closed categories were composed of the roles played by the routine presented by Milagres (2011): routines such as 
coordination, control and coherence; that act as a trigger; that minimize conflict; that decrease uncertainty; that incorporate knowledge; and, finally, they reduce the use of cognitive resources. Based on these categories, both the UFSC laboratories and the Petrobras laboratories have identified the role of routines in the technological learning that exists in this interaction between university and company.

The data analysis was performed according to the model by Triviños (2007), which consists of pre-analysis, analytical description and referential interpretation. After grouping the related materials, the results of the interviews and the secondary data from the researched projects on the FAPEU and FEESC sites, as well as information collected on the Petrobras and UFSC laboratories sites analyzed (LMPT, LABMETRO, LABTUCAL, POLO, REMAS and LACI), the results were described, analyzed and interpreted.

\section{4. innovative procedures and technological learning inter- action UFSC and Petrobras}

The innovative search, routine and selection procedures allow the emergence and consolidation of the technological paradigm and trajectory. The search and selection allow the routines suitable for organizations to be found. The creation of activity routines in a company is important, because it allows the accumulation of specific operational knowledge, creating a memory that allows differentiation of companies and a more effective performance (NELSON, 2006). Considering the relevance of these aspects for the University and the company, the main routines present in the laboratories of UFSC and CENPES/ Petrobras linked to the interaction process with UFSC are reported below, and later the main technological learnings of this partnership are presented.

\subsection{The role of routines in UFSC laboratories}

Among the main routines identified in the UFSC laboratories that interact with Petrobras, the following can be highlighted: the composition of the team, the division of tasks by specialty, allocation of project themes for dissertations and theses, periodic group meetings, production scientific participation in events based on the results of research projects, and periodic meetings with company participants to monitor the development of the project and readjust the objectives.

The composition of the team is carried out with a balance between the number of professors, students, engineers, technicians, researchers and the operational part, which results in two essential aspects for the best technological development: the guarantee that there are permanent researchers to disseminate knowledge and the existing routines for new project members, which are renewed as students graduate, or due to the disconnection of any participant, and the tasks can be divided by specialty, ensuring continuous improvement in the performance of the task. In addition, this type of routine, according to the classification of Milagres, (2011), plays the roles of coordination, control and coherence in the group, acting as triggers, as they can trigger other routines, such as the division of tasks, and they reduce uncertainty, as they decrease the complexity of decisions.
In this type of routine, both the acquisition and accumulation of explicit knowledge, through logical deduction and its acquisition can occur through formal study, as well as tacit knowledge, which is acquired through practical experience, that is, by doing, the which means that the acquisition and accumulation of knowledge will depend on the quality and quantity of experiences, as well as on its relationship with the individual's context, as exposed by Lam (1998). In this way, in the laboratories the teams are composed of professors, students of scientific initiation, master's and doctorate, "permanent" researchers, laboratory and computer technicians, engineers and secretary, which allows the division of tasks to be by specialty, as highlighted: "we have people responsible for individual tasks for the development of technologies [E4]". Another issue raised is in relation to the effective participation of the team in more than one project, as follows: "There is a very strong transversal interaction, researchers are in more than one project [E4]". In general, the teachers are mentors of the project, students of scientific initiation are connected to the operational part of the project, for example, as a user of the software in order to test it. Master's and doctoral students have activities defined according to the theme of the dissertation and thesis projects.

The permanent researchers are linked to different tasks in the project, in order to be aware of everything that happens; the engineers are divided by specialty, there are those in the field of computing, others in mathematical modeling. The secretary is in the administrative part and the technicians in their specialties, laboratory and information technology, as explained: "Everyone participates in the project as a whole, each in their skills and competences. We have engineers, researchers and students in the field of computing, with knowledge in mathematical modeling, and we also have the most operational work. Generally, the operational work of using, being the user of the Software to do the simulations and generate the data, belongs to the scientific initiation fellows [E2] ".

According to Johnson and Lundvall (2005), tacit knowledge is linked to the individual or organization, therefore, it can only be obtained by hiring qualified individuals or by merging with other organizations, as can be identified in the composition routine of teams from the lab previously exposed. According to the classification of the routine roles of Milagres (2011), this routine allows for better coordination, control and coherence, reduces uncertainty, and minimizes conflicts, as there is a previous division of what each one within the laboratory will do, in addition to allowing them knowledge is incorporated and the use of cognitive resources is reduced, because when tasks are performed routinely, memory of the organization is created and some tasks become automatic.

It should be noted that the creation of activity routines in an organization is essential, as it allows the stock of specific operational knowledge and generates a memory capable of characterizing different organizations. The routines are tacit behaviors that are difficult to capture and encode and provide the creation of a memory in relation to the organizations' actions, which generates a more effective performance 
by this organization (NELSON, 2006). Thus, as mentioned earlier, the composition of the team and the division of tasks by specialty are routines of the laboratories that enable the creation of this memory of activities performed.

Another highlighted routine is the allocation of project themes for dissertations and thesis. The teachers try to lead the students and allocate themes that are linked to the larger project for PETROBRAS: "When we do the project, we already assume that those activities will be linked to a dissertation or thesis [E3]"; "Master's and doctoral students have the theme of his work defined in the context of the project's theme, as they are real and interesting problems to be studied, in addition to enabling the improvement of the routine of activities in the project [E1]".

The researchers also highlight the increased involvement of students, due to being real themes and being part of dissertations and theses, as explained: "Students are more involved, because they are real problems, they are applied research and are linked to their dissertations. and theses [E6] ". This routine allows the reduction of uncertainty, as according to Milagres (2011) it simplifies the complexity of decisions in relation to the activities carried out in the project and increases confidence in the adopted standards, since a more in-depth knowledge about the project's theme. In this routine identified in the laboratory, the development of explicit knowledge exposed by Lundvall (2006b) is evidenced, because considering the way of coding it and the transfer mechanism, this type of explicit knowledge can be verbalized or communicated in symbolic ways, through projects, computer programs, among others.

The group's periodic meetings allow the routine of carrying out tasks to be improved, in addition to being a moment in which joint problems related to specific tasks that end up being solved are discussed together. "We have a weekly meeting with all project members. In this way, we interact and discuss the status of activities within the project and we resolve situations that are sometimes pending in a specific task. It is a very important exchange [E3] ". This type of routine plays different roles according to the proposal of Milagres (2011), such as: the possibility of coordination, control and coherence, as weekly meetings allow activities to always remain under coordination and control, they act as triggers, because from the meetings issues arise to be resolved that can generate new routines, minimize conflicts, reduce uncertainty, and enable the incorporation of knowledge, since all questions regarding the current situation of the activities and problems to be solved are socialized and discussed in groups.

The realization of scientific production and participation in events based on the results of the research projects is another routine linked to the laboratories that partner with Petrobras and that allows the members to have a continuous improvement, which positively influences the development of the project. "Of all the projects with Petrobras, we carry out scientific production, which is published in events, and students are part of this, as we receive financial support for this participation. It is an academic activity that we have and at the same time is part of the project and allows everyone involved to update and improve their knowledge, which is automatically passed on to the activities carried out in the project, which benefits our daily lives in carrying out the activities. [E2]".

This routine makes it possible to reduce uncertainty and incorporate knowledge, since as scientific research is carried out and that the researchers participate of events, the productions are discussed, questioned and improved, and this knowledge generated from scientific production and exposure is accumulated and this learning can help in carrying out the projects.

In relation to the periodic meetings with company participants to monitor the development of the project and readjust the objectives, it is clear that this type of routine in relation to all the projects that are carried out at UFSC in partnership with Petrobras allowed no problems in relation to the results presented by the University, since, the company's own members participate and discuss what can be rethought, changed or improved in the project, avoiding waste in relation to the project's execution time and generating positive results at the end of them, as mentioned : "Throughout the year we have meetings with Petrobras engineers, as they are very participative, they are members of the project team. As I told you, we discussed the objectives, the necessary changes in the research, and solved many situations together, which allows us to have excellent results at the end of the project and within the expected time [E4] ".

This routine allows it to play the role entitled by Milagres (2011) as reducing uncertainty, as it allows this monitoring and effective participation of the project by the company to make decisions simpler, as well as bringing security in the execution of activities, because they routinely pass for company's approval. As explained, routines play different roles in the innovation process. As presented by Milagres (2011), there were identified in the routines performed at UFSC laboratories that perform interaction with Petrobras, different roles of routine, such as: coordination, control and coherence, trigger, reduction of conflict, reduction of uncertainty, absorption knowledge, and reducing the use of cognitive resources.

\subsection{The role of routines in CENPES/Petrobras laboratories}

Among the main routines identified in CENPES laboratories and sectors of the company linked to the interaction process, the following stand out: the composition of the team, the division of tasks by specialty, the definition of research according to the company's strategy, the use of SIGITEC in all stages of the project, meetings in the laboratories and periodic meetings with University participants to monitor the development of the project and readjust the objectives.

The team consists of engineers, researchers, laboratory technicians, functional managers and technological program coordinator. According to the manager "The R\&D project is developed in a matrix form, involving several disciplines, and the team is composed of various specialties and managements and it is usually coordinated by a technological program coordinator [E9]". This composition allows continuity of the existing routines in the laboratory, even if there is a change of collaborator and a variety in the specialty of the team members, 
which changes according to the need of the laboratories, which are divided into $\mathrm{R} \& \mathrm{D}$, basic engineering and technology management. The R\&D laboratories are subdivided into: geosciences, geoengineering and well engineering, production engineering, supply and biofuels, and gas, energy and sustainable development. Basic engineering consists of exploration and production, and gas, energy and supply. The composition of the group allows, in line with the Milagres classification (2011), coordination, control and coherence in the laboratory, acts as a trigger, as it can trigger other routines, such as the division of tasks, and reduces uncertainty, due to decreasing the complexity of decisions.

The division of tasks by specialty is another routine related to the CENPES laboratories that are linked to the interaction projects with UFSC, as mentioned: "There is a division of activities in the laboratories involved with the research projects that occurs according to the specialty of each collaborator, such as engineers and technicians of several different qualifications, as well as the technological program coordinator [E8] "; "The division of tasks occurs between the members of the laboratories, who have different specialties, and, in general, they are linked to more than one project at the same time, according to the company's needs. The technological program coordinator is responsible for monitoring all transversal actions and activities in the laboratory [E9] ". According to the classification of the routine roles of Milagres (2011), the division of tasks by specialties provides better coordination, control and coherence, reduces uncertainty, reduces conflicts, due to the division that occurs previously in the activities of each employee in the laboratory, in addition to enabling the accumulation of knowledge that culminates in reducing the use of cognitive resources, as tasks that occur repeatedly generate the organization's memory.

Another highlighted routine is the definition of surveys according to the company's business strategy, which are previously foreseen in the strategic planning and business plans and allows that through the established partnerships the goals are reached and the company's technological challenges are overcome, as explained: “The results obtained through the execution of $\mathrm{R} \& \mathrm{D}$ projects from the interaction are used by Petrobras as inputs to overcome its technological challenges [E9]" "All R\&D projects developed by Petrobras are idealized and created based on the company's business strategies, spelled out in its strategic planning and business and management plans, through the governance of technological committees in a process known as the Petrobras Technological System. With 25 years of continuous improvement, the strategic direction process ensures that strategic and business objectives are deployed in a portfolio of $R \& D$ projects aligned with the company's technological challenges [E8]".

The managers highlight the fact that researches are carried out only by the research center itself, CENPES, and also through the interaction, in which the relevance of UFSC for technological development stands out, "The company seeks to develop, internally or with technological partners, projects that contribute to your business goals. In this context, UFSC is one of Petrobras most relevant partners in the most diverse themes of its value chain [E9] ". According to the classification of Milagres (2011), this routine allows coordination, control and coherence, as it guides the company's actions, sequences and uniformity; minimizes conflicts and reduces uncertainty, as it defines previously the researches related to the strategies, in this way, it is clear to those involved which the technological challenges of the company and how they will be achieved, besides simplifying the complexity of the decisions in relation to the activities carried out in the project.

With regard to the periodic meetings of the laboratory, it is emphasized that these allow the routine of performing tasks to be improved, and, in addition, it is a space for joint discussion on the problems and possible solutions for specific problems, "the laboratories carry out periodic meetings, in order to discuss aspects related to the projects and activities being carried out, in addition to being a space for exchange and adding knowledge, as issues to be resolved and possible solutions are shared [E8] "; "The meetings take place in each laboratory, but the dynamics and periodicity depend on each group and needs that exist at the moment [E9]". This routine has different roles, according to the proposal of Milagres (2011), such as: coordination, control and coherence; it acts as a trigger, insofar as issues arise to be resolved in these meetings that can give rise to new routines, minimize conflicts, reduce uncertainty, and it allows the incorporation of knowledge, due to the socialization of issues related to the project.

The use of SIGITEC is recent in the company, it started in 2011, but it already shows itself as a system that organizes the activities linked to the project, and the system's monitoring routine in all stages of the research allows greater knowledge about the project technological development proposed in each $\mathrm{R} \& \mathrm{D}$ project, not only by the company, but by the University, foundation and ANP. In addition, this system creates a habit for researchers to report everything that happens in the research and main results, enabling the creation of a memory for the organization, since all records are made available in the system, as follows: "All R\&D projects developed by PETROBRAS are linked to SIGITEC, PETROBRAS Technology Investment Management System, from the project proposal by the Universities to the delivery of the final report [E8] "; " The SIGITEC allows the company to have a memory of the projects, follow all the development and allows it to be clearer to the researchers of the University what is expected at each stage, since this is an explanatory system, in addition to facilitating control E9] ".

This routine, according to the types exposed by Milagres (2011), generates coordination, control and coherence, as it allows the company to structure itself in terms of actions; it acts as a trigger, as it raises new routines especially in the laboratories of the Universities, as the researchers create a routine to feed the system in order to ensure a successful development of the project; minimizes conflicts and reduces uncertainty, because it allows control of all parties involved in R\&D projects, in addition to simplifying and reducing the complexity of decisions; and provides the incorporation of knowledge, which culminates in technological learning, as it is a routine that generates memory for the company, due to the fact that all projects are registered.

The concomitant action of search and selection over time enables the evolution of organizations. In this sense, the creation of SIGITEC is 
the result of this search and selection process over the years in the interaction process. The selection process corresponds to the mechanism for choosing the innovations exercised by the environment. Considering the flow of new innovations, the selection environment dictates the ways of adopting technologies over time (DOSI, 2006; NELSON; WINTER, 2006).

With regard to periodic meetings with University participants to monitor the development of the project and readjust the objectives, it can be said that this type of routine in relation to the projects that are carried out by PETROBRAS, made it possible to minimize possible problems as a result of the projects, respected deadlines and what the expected results were achieved, as the PETROBRAS manager reports: "In this interaction process with UFSC, The PETROBRA's researchers really participate, they are always at the University talking with the professors, with the project team, holding meetings, discussing the results, this is very effective [E9] "; "These meetings and visits carried out by PETROBRAS researchers are constant and allow for the readjustment of the project, when necessary, in addition to avoiding problems, wasting time, resources, and bringing positive results. It is a joint effort between the company and the University [E8] ".

In the routine described, the presence of one of the types of knowledge exposed by Lundvall (2006a) is visualized, the know-how, which is essential in economic activities and includes the ability to do something specific based on standards linked to learning and experience of the individual. This routine plays the role entitled by Milagres (2011) as reducing uncertainty, since it allows the company to monitor and effectively participate in the project, a fact that simplifies decisions and creates security in carrying out activities. As explained, the routines have different roles in the innovation process. Therefore, a table is presented next with the main roles of the routines and their description, proposed by Milagres (2011), as well as the correlation with the routines identified in the UFSC and CENPES / Petrobras laboratories and company sectors related to the interaction.

Chart 2. The roles of the UFSC and Petrobras interaction routine

\begin{tabular}{|c|c|c|c|}
\hline Roles & Description & Routines identified in UFSC laboratories & $\begin{array}{l}\text { Routines identified in CENPES/ Petrobras la- } \\
\text { boratories }\end{array}$ \\
\hline $\begin{array}{l}\text { Provide coordina- } \\
\text { tion, control and } \\
\text { coherence }\end{array}$ & $\begin{array}{l}\text { Routines provide structure for the } \\
\text { company's actions, sequences and } \\
\text { uniformity. }\end{array}$ & $\begin{array}{l}\text {-composition of the team; } \\
\text {-division of tasks by specialty; } \\
\text {-periodic group meetings; }\end{array}$ & $\begin{array}{l}\text {-composition of the team, } \\
\text {-division of tasks by specialty, } \\
\text { - definition of research based on the company's } \\
\text { business strategy; } \\
\text { - periodic meetings of the laboratory, } \\
\text { - use of SIGITEC. }\end{array}$ \\
\hline Act as triggers & $\begin{array}{l}\text { They can be triggered and trigger } \\
\text { other routines. }\end{array}$ & $\begin{array}{l}\text {-composition of the team; } \\
\text { - periodic group meetings. }\end{array}$ & $\begin{array}{l}\text {-composition of the team; } \\
\text { - periodic meetings of the laboratory; } \\
\text { - use of SIGITEC. }\end{array}$ \\
\hline Minimize conflicts & $\begin{array}{l}\text { Routines mediate issues related to } \\
\text { the power struggle and conflicts. }\end{array}$ & $\begin{array}{l}\text { - division of tasks by specialty; } \\
\text { - periodic group meetings. }\end{array}$ & $\begin{array}{l}\text { - -division of tasks by specialty; } \\
\text {-- periodic meetings of the laboratory; } \\
\text { - definition of research based on the company's } \\
\text { business strategy; } \\
\text { - use of SIGITEC. }\end{array}$ \\
\hline $\begin{array}{l}\text { Reduce the uncer- } \\
\text { tainty }\end{array}$ & $\begin{array}{l}\text { They simplify, reduce the complexi- } \\
\text { ty of decisions, increase confidence } \\
\text { in the standards adopted and, with } \\
\text { that, reduce the uncertainty. }\end{array}$ & $\begin{array}{l}\text { - composition of the team; } \\
\text { - division of tasks by specialty; } \\
\text {-Allocation of Project themes for dissertations } \\
\text { and thesis; } \\
\text { - periodic group meetings; } \\
\text { - scientific production and participation in } \\
\text { events; } \\
\text { - periodic meeting with company's participants. }\end{array}$ & $\begin{array}{l}\text { - composition of the team; } \\
\text { - division of tasks by specialty; } \\
\text { - definition of research based on the company's } \\
\text { business strategy; } \\
\text { - periodic meetings of the laboratory; } \\
\text { - periodic meetings with University's partici- } \\
\text { pants; } \\
\text { - use of SIGITEC. }\end{array}$ \\
\hline $\begin{array}{l}\text { Incorporate } \\
\text { Knowledge }\end{array}$ & $\begin{array}{l}\text { Routines are the memory of organi- } \\
\text { zations, the locus of knowledge. }\end{array}$ & $\begin{array}{l}\text { - division of tasks by specialty; } \\
\text { - periodic group meetings; } \\
\text {-scientific production and participation in events. }\end{array}$ & $\begin{array}{l}\text { - division of tasks by specialty; } \\
\text { - periodic meetings of the laboratory; } \\
\text { - use of SIGITEC. }\end{array}$ \\
\hline $\begin{array}{l}\text { Reduce the use of } \\
\text { cognitive resource }\end{array}$ & $\begin{array}{l}\text { Routines allow automatic actions } \\
\text { and thereby free up cognitive space. }\end{array}$ & division of tasks by specialty. & - division of tasks by specialty. \\
\hline
\end{tabular}

Source: Elaborated by the authors, from Milagres, 2011

It can be seen when analyzing table 2, which summarizes the exposure of the roles of routines in the laboratories of UFSC and CENPES / Petrobras, which is very similar in the identification of routines, which may be the result of a maturity in the interaction process, the result of a partnership that is characterized by its historical trajectory in the development of new technologies. 


\subsection{Technological learning resulting from UFSC and Petrobras interaction}

From the search, routine and selection, the technological learning process is generated, which can be elucidated from the understanding that the economic environment is constantly evolving and the change processes are endowed with characteristics such as irreversibility and cumulativeness, essential for the generation of innovation. The learning is a cumulative process internal or external to the organization, commonly path dependent, since the assimilation of advanced information depends on the past trajectory.

Among the main learnings resulting from the routines of UFSC research laboratories that interact with PETROBRAS, it is possible to highlight the learning in the laboratory with permanent researchers who pass on information to new collaborators, making it possible to advance in the accumulated knowledge from sharing knowledge, as described in the division of tasks by specialty, and the learning linked to the discussion of problems and solutions in the weekly meetings of the group itself, where the routine of performing tasks and solving problems is improved and shared, allowing continuous learning.

These routines together play all the roles listed by Milagres (2011), coordination, control and coherence, the trigger for new routines, minimize conflicts, reduce uncertainty, incorporate knowledge and decrease the use of resources. Together they generate learning, it is called learning by searching, which according to Malerba (1992) and Tigre (2006) is internal to the organization and occurs through processes of information search and R\&D activities that lead to problem solving and aggregation of new knowledge, and it aims to bring about incremental and radical innovations.

It was also identified the learning called learning by interacting, which is the combination of learning by doing (internal learning to the organization - by production) and learning by using (learning from the market - by use). This learning takes place in the group through technical visits and discussion of the objectives and directions of the project with the company, as both experiences, the group in which the project is developed and the company that has the demands and needs linked to the sector in which it operates, are articulated to generate learning. According to Rosenberg (2006), this learning, resulting from a routine that has the role of reducing uncertainty, has been widely used by high technology sectors, as it results from the qualified exchange of information between those involved. This partnership generates interactional learning, technological information flows and innovative partnerships.

The learning through meetings and congresses, which take place for all group participants and are characterized as one of the routines that reduce uncertainty and enable the incorporation of knowledge, is called by Malerba (1992) and Tigre (2006) as learning from advances in science and technology, which is external to the organization and is related to the absorption of new knowledge from the international S\&T system, which occurs through knowledge accumulated in these events in which specialists in the area discuss topics of interest related to research projects (MALERBA, 1992; TIGRE, 2006).
Among the main lessons learned from the routines of CENPES / PETROBRAS research laboratories that interact with UFSC, the learning resulting from the discussion of problems and solutions at the meetings held at CENPES / PETROBRAS laboratories, in which the routine of carrying out the activities and problem solving is enhanced and shared, resulting in continuous learning. The identified learning is characterized as learning by searching according to Malerba (1992), and for Tigre (2006) it is internal to the organization, resulting from processes of searching for information and R\&D activities, which provide problem solving and accumulation of new ones. knowledge in order to generate innovations.

The technical visits and discussion of the project's objectives in conjunction with the University, which take place in the periodic meetings between the interaction partners and exercise the role of reducing uncertainty, generate learning by interacting learning according to Malerba (1992), because the experiences the members of the company's laboratory who know the demands inherent to the Oil and Gas Sector and the research group at the University where the project is developed culminate in the generation of new learning. This specific type is the combination of learning by doing (internal learning to the organization - by production) and learning by using (learning from the market - by use). According to Rosenberg (2006), this learning is common in high technology sectors since the qualified sharing of experiences and information enables the generation of innovation.

Corroborating with the exposed by Malerba and Orsegino (1993) and Cassiolato, Campos and Stallivieri (2007), the formal and informal transmission of knowledge in the learning processes was identified in the UFSC and Petrobras interaction. These processes extrapolated the formal activities of RD\&I, which are characterized by the dissemination of codified knowledge and appropriation by the company, and also involved learning from informal sources, characterized by mechanisms that enable interactions between companies and other agents and in which knowledge is widespread and is not freely appropriable, thus requiring observation and practice.

\section{Conclusions}

The technological advances in the interaction between UFSC and PETROBRAS were due to routines and learning, institutional and technological transformations, the technological regime and the sectorial pattern of innovation to which the company is linked and the government actions that regulated the interaction process, as well as investments in the sector. In this sense, the present study sought to identify the role of routines in the technological learning of this interaction.

Regarding the main routines in the UFSC laboratories, the composition of the team was identified, division of tasks by specialty, periodic group meetings, allocation of project themes for dissertations and theses, scientific production and participation in events and periodic meetings with company's participants. In the CENPES / Petrobras laboratories, in addition to these routines already exposed, the research definition routines were identified according to the company's business strategy and the use of SIGITEC. These routines together at both 
UFSC and Petrobras play all the roles of the routines listed by Milagres (2011), coordination, control and coherence, the trigger for new routines, conflict's reduction, decrease in uncertainty, incorporation of knowledge and minimizing the use of cognitive resources.

Among the main technological learnings of the interaction under study due to the identified routines, the learning that occurs through meetings and congresses in which all members of the group participate and are characterized as one of the routines that reduce uncertainty and enable incorporation is highlighted. knowledge, it is called as learning from advances in science and technology.

The creation of routines such as the composition of the team, division of tasks by specialty, periodic meetings of the group and with the institution with which it interacts, led to the generation of learning by searching and learning by interacting, both at the University and at the company. These learnings enabled the generation of faster innovations through partnership and institutional transformations that improve and facilitate the interaction process between UFSC and Petrobras, such as the implementation of SIGITEC itself.

Among these, there is the possibility of replicating research in other sectors, in which institutions behave differently, in order to understand how the different roles exercised by routine generate the technological learning process in partnerships that have a long history trajectory of interaction and accumulation of knowledge.

\section{References}

Arroio, A. Conhecimento, sistema de inovação e desenvolvimento. Rio de Janeiro: Editora UFRJ; Contraponto, p. 83-130, 2005.

Cassiolato, J. E; Campos, R. R; Stallivieri, F. Processos de aprendizagem e inovação em setores tradicionais: Os arranjos produtivos locais de confecções no Brasil. Economia, Brasília (DF), v.7, n.3, p.477-502, set/dez. 2007.

Corazza, R. I.; Fracalanza, P. S. Caminhos do pensamento neoschumpeteriano: para além das analogias biológicas. Nova Economia, Belo Horizonte, v. 14, n. 2, p. 127-155, maio/ago. 2004.

Dosi, G. Mudança técnica e Transformação Industrial. Campinas: Ed. Unicamp, 2006.

Dosi, G., Teece, D. J., Winter, S. Toward a Theory of Corporate Coherence: Preliminary Remarks. In DOSI, G; GIANETTI, R.; TONIELLI, P. M. Tecnology and Interprise in Historical Perspective. Oxford: Clarendon Press, 1992.
Johnson, B.; Lundvall, B. Promovendo sistemas de inovação como resposta à economia do aprendizado crescentemente globalizada.In: LASTRES, M.H.; CASSIOLATO, J.E;

Lam, A. Tacit knowledge, Organisational Learning and Innovation: a societal perspective. In: DRUID, 1998.

Lundvall, B. One knowledge base or many knowledge pools? In: DRUID. 2006a.

Knowledge Management in the Learning Economy. In: DRUID, 2006b.

Malerba , F. Learning by firms and incremental technical change. The Economic Journal, p. 845-859, 1992.

Malerba, F.; Orsenigo, L. Technological Regimes and Firm Behavior. Industrial and Corporate Change, v.2, n.1, 1993.

Milagres, R. Rotinas - Uma revisão teórica. Revista Brasileira de Inovação, Campinas (SP), 10 (1), p.161-196, janeiro/junho 2011.

NELSON, R. R. As fontes do crescimento econômico. Campinas: Unicamp, 2006.

Nelson, R; Winter, S.G. An evolutionary theory af economic change. Estados Unidos: Harvard U. P, 1982.

Uma Teoria evolucionária da mudança econômica . Campinas: Unicamp, 2006.

Nonaka, I.; Takeuchi, H.. The knowledge creating company. New York: Oxford University Press, 1995.

Possas, M. L. Economia evolucionária neo-schumpeteriana: elementos para uma integração micro-macrodinâmica. Estudos Avançados, v. 22 , n. $63,2008$.

Rosenberg, N. Por dentro da caixa preta: Tecnologia e Economia. Campinas: Unicamp, 2006.

Suzigan, W.; Albuquerque, E. M.; Cario, S. A. F. Em busca de inovação: interação universidade-empresa no Brasil. Belo Horizonte: Autêntica Editora, 2011.

Tigre, P. B. Gestão da Inovação: a economia da tecnologia do Brasil. Rio de Janeiro: Elsevier, 282p, 2006.

Triviños, A.N. S. Introdução à pesquisa em ciências sociais: a pesquisa qualitativa em educação. 1. ed. São Paulo: Atlas, 2007. 
